J. Nonlinear Var. Anal. 5 (2021), No. 1, pp. 155-177

Available online at http://jnva.biemdas.com

https://doi.org/10.23952/jnva.5.2021.1.10

\title{
AN EXISTENCE RESULT FOR A PERIODIC BOUNDARY VALUE PROBLEM OF FRACTIONAL SEMILINEAR DIFFERENTIAL EQUATIONS IN A BANACH SPACE
}

\author{
MIKHAIL KAMENSKII ${ }^{1}$, GARIK PETROSYAN ${ }^{2}$, CHING-FENG WEN WH, $^{3, *}$ \\ ${ }^{1}$ Faculty of Mathematics, Voronezh State University, Voronezh 394018, Russia \\ ${ }^{2}$ Research Center of Voronezh State University of Engineering Technologies, and Faculty of Physics and \\ Mathematics, Voronezh State Pedagogical University, Voronezh 394043, Russia \\ ${ }^{3}$ Center for Fundamental Science, Research Center for Nonlinear Analysis and Optimization, \\ Kaohsiung Medical University, Kaohsiung, 80708, Taiwan \\ ${ }^{4}$ Department of Medical Research, Kaohsiung Medical University Hospital, Kaohsiung, 80708, Taiwan
}

\begin{abstract}
We consider the periodic boundary value problem for a semilinear differential equation of a fractional order $q \in(1,2)$ in a Banach space. We prove auxiliary statements about fractional derivatives. To solve this problem, we introduce the integral operator whose fixed points coincide with mild solutions of our problem. An existence result is established.
\end{abstract}

Keywords. Fractional differential equation; Fixed point; Measure of noncompactness; Periodic problem; Semilinear differential equation.

\section{INTRODUCTION}

The theory of differential equations of a fractional order arises from Leibnitz and Euler. Recently, it has been under the spotlight due to its real applications in applied mathematics, physics, engineering, biology, economics and other branches of natural sciences; see, e.g., [1][21] and the references therein. In [12], the authors proved local and global existence results for a semilinear differential inclusion in a Banach space of a fractional order $q \in(0,1)$, and demonstrated the compactness of the solution set and its continuous dependence on parameters.

It is well known that one of the most important boundary value problems is the periodic one. Let us give a short survey of the results achieved in this direction. In [22], by using the Green function method and the fixed point theorems of Schaeffer and Banach, Belmekki, Nieto and Rodriguez-Lopez considered the following boundary value problem for a nonlinear fractional differential equation of the form

$$
\begin{gathered}
D^{q} x(t)-\lambda x(t)=f(t, x(t)), \quad t \in(0,1], \quad q \in(0,1), \\
\lim _{t \rightarrow 0+} t^{1-q} x(t)=x(1),
\end{gathered}
$$

\footnotetext{
${ }^{*}$ Corresponding author.

E-mail addresses: mikhailkamenski@mail.ru (M. Kamenskii), garikpetrosyan@yandex.ru (G. Petrosyan), cfwen@kmu.edu.tw (C.F. Wen).

Received September 7, 2020; Accepted November 22, 2020.

(C)2021 Journal of Nonlinear and Variational Analysis
} 
where $D^{q}$ is the Riemann-Liouville fractional derivative, $f:(0,1] \times \mathbb{R} \rightarrow \mathbb{R}$ is a continuous function, and $\lambda \in \mathbb{R}$. Belmekki, Nieto and Rodriguez-Lopez also considered a similar periodic boundary value problem with impulse effects in [23] recently.

In [24], by using the Green function method, Bai and Lu considered the existence and multiplicity of positive solutions to a boundary value problem of a nonlinear fractional differential equation

$$
\begin{gathered}
D^{q} x(t)+f(t, x(t))=0, \quad t \in[0,1], \quad q \in(1,2), \\
x(0)=x(1)=0,
\end{gathered}
$$

where $D^{q}$ is the Riemann-Liouville fractional derivative, and $f:[0,1] \times[0,+\infty) \rightarrow[0,+\infty)$ is a continuous function.

The periodic boundary value problem for a semilinear differential inclusions in Banach spaces of a fractional order $q \in(0,1)$ was investigated in [13] via the method of the translation multioperator along the trajectories of an inclusion.

In a separable Banach space $E$, for a semilinear fractional order $q \in(1,2)$ differential equation of the form

$$
{ }^{C} D^{q} x(t)=\lambda x(t)+f(t, x(t)), \quad t \in[0, T],
$$

by using the Green function method, we, in this paper, consider the problem of the existence of a mild solution satisfying the following periodic boundary value conditions

$$
x(0)=x(T), \quad x^{\prime}(0)=x^{\prime}(T),
$$

where ${ }^{C} D^{q}$ denotes the Caputo fractional derivative, $\lambda>0$, and $f:[0, T] \times E \rightarrow E$ is a nonlinear map.

The paper is organized in the following way. In Section 2, we present necessary notions and facts from the fractional analysis and from the theory of condensing maps. In Section 3, we construct the Green function for the above problem. In Section 4, the last section, we introduce and study the integral operator whose fixed points coincide with mild solutions of our problem. Then, we prove the main existence result (Theorem 4.2, see below).

\section{PRELIMINARIES}

2.1. Differential equations of a fractional order. First, we will introduce the necessary definitions and notations from fractional analysis (more detailed can be found in monographs $[3,4,6])$.

Definition 2.1. The Riemann-Liouville fractional integral of an order $q>0$ of a function $g$ : $[0, T] \rightarrow E$ is the function $I^{q} g$ of the following form:

$$
I^{q} g(t)=\frac{1}{\Gamma(q)} \int_{0}^{t}(t-s)^{q-1} g(s) d s
$$

where $\Gamma$ is the Euler gamma-function

$$
\Gamma(q)=\int_{0}^{\infty} x^{q-1} e^{-x} d x
$$

Notice that the following property holds for the Euler gamma-function (see, e.g., [4]):

$$
\frac{1}{\Gamma(q)}=0, \quad q=0,-1,-2, \ldots
$$


Definition 2.2. The Riemann-Liouville fractional derivative of an order $q \geq 0$ of a function $g:[0, T] \rightarrow E$ is the function $D^{q} g$ of the following form:

$$
D^{q} g(t)=\frac{1}{\Gamma(n-q)}\left(\frac{d}{d t}\right)^{n} \int_{0}^{t}(t-s)^{n-q-1} g(s) d s, \quad n=[q]+1,
$$

provided that the right-hand side of this equality is well defined.

Definition 2.3. The Caputo fractional derivative of an order $q \geq 0$ of a function $g \in C^{n}([0, T] ; E)$ is the function ${ }^{C} D_{0}^{q} g$ of the following form:

$$
{ }^{C} D_{0}^{q} g(t)=\frac{1}{\Gamma(n-q)} \int_{0}^{t}(t-s)^{n-q-1} g^{(n)}(s) d s, \quad n=[q]+1 .
$$

provided that the right-hand side of this equality is well defined.

The Caputo fractional derivative of an order $q \geq 0$ of a function $g$ on $[a, b]$ is related to the Riemann-Liouville fractional derivative of the same order by the following relation:

$$
{ }^{C} D^{q} g(t)=\left(D^{q}\left(g(s)-\sum_{k=0}^{n-1} \frac{g^{(k)}(a)}{k !}(s-a)^{k}\right)\right)(t) .
$$

A great advantage of the Caputo fractional derivative, in comparison with the RiemannLiouville fractional derivative, is the preservation of the main properties of the classic derivative, for example, the equality to zero of the derivative of a constant function.

Definition 2.4. A function of the form

$$
E_{q, \beta}(z)=\sum_{n=0}^{\infty} \frac{z^{n}}{\Gamma(q n+\beta)}, \quad q>0, \beta \in \mathbb{C}, z \in \mathbb{C}
$$

is called the Mittag-Leffler function.

Denote $E_{q, 1}$ by $E_{q}$. The Mittag-Leffler function is important in fractional calculus. Consider the Cauchy problem for a scalar differential equation of a fractional order

$$
\begin{gathered}
{ }^{C} D^{q} x(t)=\lambda x(t)+f(t), \quad t \in[0, T], \quad 1<q<2, \\
x(0)=c_{1}, \quad x^{\prime}(0)=c_{2},
\end{gathered}
$$

where $\lambda \in \mathbb{R}$, and $f:[0, T] \rightarrow \mathbb{R}$ is a function for which $I^{q} f$ exists. The solution to problem (2.2)-(2.3) is a continuous function $x:[0, T] \rightarrow \mathbb{R}$ satisfying condition (2.3) such that the Caputo fractional derivative ${ }^{C} D^{q} x$ is a continuous function satisfying equation (2.2). It is well known (see [3]) that the unique solution of this problem is the function

$$
x(t)=c_{1} E_{q}\left(\lambda t^{q}\right)+c_{2} t E_{q, 2}\left(\lambda t^{q}\right)+\int_{0}^{t}(t-s)^{q-1} E_{q, q}\left(\lambda(t-s)^{q}\right) f(s) d s .
$$

Note (see $[1,6])$ that the following relations holds true

$$
\begin{gathered}
E_{q, \beta}(t)=\frac{1}{\Gamma(\beta)}+t E_{q, \beta+q}(t), \\
\left(\frac{d}{d t}\right)^{n}\left(t^{\beta-1} E_{q, \beta}\left(\lambda t^{q}\right)\right)=t^{\beta-n-1} E_{q, \beta-n}\left(\lambda t^{q}\right), \\
\int_{0}^{z} t^{\beta-1} E_{q, \beta}\left(\lambda t^{q}\right) d t=z^{\beta} E_{q, \beta+1}\left(\lambda z^{q}\right) .
\end{gathered}
$$

We also need the following lemma. 
Lemma 2.1. If $f \in C([0, T] ; E)$, then the equality

$$
\left(\frac{d}{d t}\right)\left(\int_{0}^{t}(t-s)^{q-1} E_{q, q}\left(\lambda(t-s)^{q}\right) f(s) d s\right)=\int_{0}^{t}(t-s)^{q-2} E_{q, q-1}\left(\lambda(t-s)^{q}\right) f(s) d s
$$

holds.

Proof. Notice that the function $\frac{\partial}{\partial t}(t-s)^{q-1} E_{q, q}\left(\lambda(t-s)^{q}\right) f(s)$ is not continuous at $t=s$. Therefore, it is necessary to present the initial integral as the sum:

$$
\begin{aligned}
& \int_{0}^{t}(t-s)^{q-1} E_{q, q}\left(\lambda(t-s)^{q}\right) f(s) d s \\
& =\int_{0}^{t-d}(t-s)^{q-1} E_{q, q}\left(\lambda(t-s)^{q}\right) f(s) d s+\int_{t-d}^{t}(t-s)^{q-1} E_{q, q}\left(\lambda(t-s)^{q}\right) f(s) d s \\
& =I_{1}+I_{2},
\end{aligned}
$$

for $0<d<t$.

For $I_{1},(t-s)^{q-1} E_{q, q}\left(\lambda(t-s)^{q}\right) f(s)$ and $\frac{\partial}{\partial t}(t-s)^{q-1} E_{q, q}\left(\lambda(t-s)^{q}\right) f(s)$ are continuous. So, we can easily find the derivative of $I_{1}$ by using formula (2.6) and the well known theorem from mathematical analysis:

$$
\begin{aligned}
\left(\frac{d}{d t}\right)\left(\int_{0}^{t-d}(t-s)^{q-1} E_{q, q}\left(\lambda(t-s)^{q}\right) f(s) d s\right) \\
=\int_{0}^{t-d}\left(\frac{d}{d t}\right)\left((t-s)^{q-1} E_{q, q}\left(\lambda(t-s)^{q}\right) f(s)\right) d s \\
\quad+(t-t+d)^{q-1} E_{q, q}\left(\lambda(t-t+d)^{q}\right) f(t+d)-0 \cdot(t)^{q-1} E_{q, q}\left(\lambda(t)^{q}\right) f(0) \\
=\int_{0}^{t-d}(t-s)^{q-2} E_{q, q-1}\left(\lambda(t-s)^{q}\right) f(s) d s+d^{q-1} E_{q, q}\left(\lambda d^{q}\right) f(t+d) .
\end{aligned}
$$

Now let us find the derivative of $I_{2}$. Assuming without loss of generality that $0<h<d$, we have

$$
\begin{aligned}
I_{2}^{\prime}(t)= & \lim _{h \rightarrow 0} \frac{1}{h}\left(\int_{t+h-d}^{t}(t+h-s)^{q-1} E_{q, q}\left(\lambda(t+h-s)^{q}\right) f(s) d s\right. \\
& +\int_{t}^{t+h}(t+h-s)^{q-1} E_{q, q}\left(\lambda(t+h-s)^{q}\right) f(s) d s \\
& \left.-\int_{t-d}^{t+h-d}(t-s)^{q-1} E_{q, q}\left(\lambda(t-s)^{q}\right) f(s) d s-\int_{t+h-d}^{t}(t-s)^{q-1} E_{q, q}\left(\lambda(t-s)^{q}\right) f(s) d s\right) \\
= & \lim _{h \rightarrow 0} \frac{1}{h}\left(\int_{t+h-d}^{t}(t+h-s)^{q-1} E_{q, q}\left(\lambda(t+h-s)^{q}\right) f(s) d s\right. \\
& \left.-\int_{t+h-d}^{t}(t-s)^{q-1} E_{q, q}\left(\lambda(t-s)^{q}\right) f(s) d s\right) \\
& +\lim _{h \rightarrow 0} \frac{1}{h}\left(\int_{t-d}^{t+h-d}(t+h-s)^{q-1} E_{q, q}\left(\lambda(t+h-s)^{q}\right) f(s) d s\right. \\
& \left.-\int_{t-d}^{t+h-d}(t-s)^{q-1} E_{q, q}\left(\lambda(t-s)^{q}\right) f(s) d s\right)
\end{aligned}
$$




$$
\begin{aligned}
& +\lim _{h \rightarrow 0} \frac{1}{h}\left(\int_{t}^{t+h}(t+h-s)^{q-1} E_{q, q}\left(\lambda(t+h-s)^{q}\right) f(s) d s\right. \\
& \left.-\int_{t-d}^{t+h-d}(t+h-s)^{q-1} E_{q, q}\left(\lambda(t+h-s)^{q}\right) f(s) d s\right) \\
= & \lim _{h \rightarrow 0} \frac{1}{h}\left(\int_{t+h-d}^{t}\left((t+h-s)^{q-1} E_{q, q}\left(\lambda(t+h-s)^{q}\right) f(s)-(t-s)^{q-1} E_{q, q}\left(\lambda(t-s)^{q}\right) f(s)\right) d s\right) \\
& +\lim _{h \rightarrow 0} \frac{1}{h}\left(\int _ { t - d } ^ { t + h - d } \left((t+h-s)^{q-1} E_{q, q}\left(\lambda(t+h-s)^{q}\right) f(s)\right.\right. \\
& \left.\left.-(t-s)^{q-1} E_{q, q}\left(\lambda(t-s)^{q}\right) f(s)\right) d s\right) \\
& +\lim _{h \rightarrow 0} \frac{1}{h}\left(\int_{t}^{t+h}(t+h-s)^{q-1} E_{q, q}\left(\lambda(t+h-s)^{q}\right) f(s) d s\right. \\
& \left.-\int_{t-d}^{t+h-d}(t+h-s)^{q-1} E_{q, q}\left(\lambda(t+h-s)^{q}\right) f(s) d s\right) \\
= & \lim _{h \rightarrow 0} \frac{1}{h}\left(\int_{t-d}^{t}\left((t+h-s)^{q-1} E_{q, q}\left(\lambda(t+h-s)^{q}\right) f(s)-(t-s)^{q-1} E_{q, q}\left(\lambda(t-s)^{q}\right) f(s)\right) d s\right) \\
& +\lim _{h \rightarrow 0} \frac{1}{h}\left(\int_{t}^{t+h}(t+h-s)^{q-1} E_{q, q}\left(\lambda(t+h-s)^{q}\right) f(s) d s\right. \\
& \left.-\int_{t-d}^{t+h-d}(t+h-s)^{q-1} E_{q, q}\left(\lambda(t+h-s)^{q}\right) f(s) d s\right) .
\end{aligned}
$$

From the conditions of the lemma, we can apply the Lebesgue theorem to the first term of the last relation

$$
\begin{aligned}
& \lim _{h \rightarrow 0} \frac{1}{h}\left(\int_{t-d}^{t}\left((t+h-s)^{q-1} E_{q, q}\left(\lambda(t+h-s)^{q}\right) f(s)-(t-s)^{q-1} E_{q, q}\left(\lambda(t-s)^{q}\right) f(s)\right) d s\right) \\
& =\int_{t-d}^{t} \lim _{h \rightarrow 0} \frac{1}{h}\left((t+h-s)^{q-1} E_{q, q}\left(\lambda(t+h-s)^{q}\right) f(s)-(t-s)^{q-1} E_{q, q}\left(\lambda(t-s)^{q}\right) f(s)\right) d s \\
& =\int_{t-d}^{t}\left(\frac{d}{d t}\right)\left((t-s)^{q-1} E_{q, q}\left(\lambda(t-s)^{q}\right) f(s)\right) d s \\
& =\int_{t-d}^{t}(t-s)^{q-2} E_{q, q-1}\left(\lambda(t-s)^{q}\right) f(s) d s .
\end{aligned}
$$

Now, we find the estimate of the limits

$$
\lim _{h \rightarrow 0}\left\|\frac{1}{h}\left(\int_{t}^{t+h}(t+h-s)^{q-1} E_{q, q}\left(\lambda(t+h-s)^{q}\right) f(s) d s\right)\right\|
$$

and

$$
\lim _{h \rightarrow 0}\left\|\frac{1}{h}\left(\int_{t-d}^{t+h-d}(t+h-s)^{q-1} E_{q, q}\left(\lambda(t+h-s)^{q}\right) f(s) d s\right)\right\| .
$$


Let us estimate the first of them

$$
\begin{aligned}
& \lim _{h \rightarrow 0}\left\|\frac{1}{h}\left(\int_{t}^{t+h}(t+h-s)^{q-1} E_{q, q}\left(\lambda(t+h-s)^{q}\right) f(s) d s\right)\right\| \\
& \leq \lim _{h \rightarrow 0} \frac{\|f\|_{\infty} E_{q, q}\left(\lambda(2 T)^{q}\right)}{h} \int_{t}^{t+h}(t+h-s)^{q-1} d s \\
& =\lim _{h \rightarrow 0} \frac{\|f\|_{\infty} E_{q, q}\left(\lambda(2 T)^{q}\right)}{h} \int_{0}^{h} \tau^{q-1} d \tau \\
& =\lim _{h \rightarrow 0} \frac{\|f\|_{\infty} E_{q, q}\left(\lambda(2 T)^{q}\right)}{h} \frac{h^{q}}{q} \\
& =\lim _{h \rightarrow 0} h^{q-1}\|f\|_{\infty} E_{q, q}\left(\lambda(2 T)^{q}\right)=0 .
\end{aligned}
$$

Now, we find the estimate of the second limit

$$
\begin{aligned}
& \lim _{h \rightarrow 0}\left\|\frac{1}{h}\left(\int_{t-d}^{t+h-d}(t+h-s)^{q-1} E_{q, q}\left(\lambda(t+h-s)^{q}\right) f(s) d s\right)\right\| \\
& \leq \lim _{h \rightarrow 0} \frac{\|f\|_{\infty} E_{q, q}\left(\lambda(2 T)^{q}\right)}{h} \int_{t-d}^{t+h-d}(t+h-s)^{q-1} d s \\
& =\lim _{h \rightarrow 0} \frac{\|f\|_{\infty} E_{q, q}\left(\lambda(2 T)^{q}\right)}{h} \int_{d}^{h+d} \tau^{q-1} d \tau \\
& =\lim _{h \rightarrow 0} \frac{\|f\|_{\infty} E_{q, q}\left(\lambda(2 T)^{q}\right)}{h} \frac{(h+d)^{q}-d^{q}}{q} \\
& =\lim _{h \rightarrow 0}\|f\|_{\infty} E_{q, q}\left(\lambda(2 T)^{q}\right) \frac{q(h+d)^{q-1}}{q} \\
& =d^{q-1}\|f\|_{\infty} E_{q, q}\left(\lambda(2 T)^{q}\right),
\end{aligned}
$$

since $d$ can be taken arbitrarily, for $I_{2}$, we have

$$
\left(\frac{d}{d t}\right)\left(\int_{t-d}^{t}(t-s)^{q-1} E_{q, q}\left(\lambda(t-s)^{q}\right) f(s) d s\right)=\int_{t-d}^{t}(t-s)^{q-2} E_{q, q-1}\left(\lambda(t-s)^{q}\right) f(s) d s .
$$

Gathering the evaluations above, we get

$$
\begin{aligned}
& \left(\frac{d}{d t}\right)\left(\int_{0}^{t}(t-s)^{q-1} E_{q, q}\left(\lambda(t-s)^{q}\right) f(s) d s\right) \\
& =\int_{0}^{t-d}(t-s)^{q-2} E_{q, q-1}\left(\lambda(t-s)^{q}\right) f(s) d s+\int_{t-d}^{t}(t-s)^{q-2} E_{q, q-1}\left(\lambda(t-s)^{q}\right) f(s) d s \\
& \quad+d^{q-1} E_{q, q}\left(\lambda d^{q}\right) f(t+d) \\
& =\int_{0}^{t}(t-s)^{q-2} E_{q, q-1}\left(\lambda(t-s)^{q}\right) f(s) d s+d^{q-1} E_{q, q}\left(\lambda d^{q}\right) f(t+d) .
\end{aligned}
$$

Now, tending $d \rightarrow 0$, we obtain the desired result.

To prove the similar result for a function $f \in L^{\infty}([0, T] ; E)$, we need the following statements.

Lemma 2.2. [25] For every $f \in L^{\infty}([0, T] ; E)$, the set of its Lebesgue points is the set of full measure for $[0, T]$. 
Lemma 2.3. For every $f \in L^{\infty}([0, T] ; E)$, there is a sequence $\left\{f_{n}\right\} \subset C([0, T] ; E)$ such that $f_{n}(t) \rightarrow f(t)$ at all Lebesgue points of the function $f$ from $[0, T]$. Moreover, $\left\|f_{n}\right\|_{C([0, T] ; E)} \leq$ $\|f\|_{L^{\infty}([0, T] ; E)}$.

An example of such a sequence is the following one, constructed based on the Steklov projector

$$
\begin{gathered}
f_{n}(t)= \begin{cases}\frac{1}{2 n} \int_{t-\frac{1}{n}}^{t+\frac{1}{n}} \hat{f}(s) d s, & t \in[0, T], \\
0, & t \notin[0, T],\end{cases} \\
\hat{f}(t)= \begin{cases}f(t), & t \in[0, T], \\
0, & t \notin[0, T] .\end{cases}
\end{gathered}
$$

We also need the following classical result.

Lemma 2.4. [26] Let all the functions $\phi_{n}$ be differentiable on the interval $[0, T]$ and the sequence of derivatives $\left\{\phi_{n}^{\prime}\right\}$ be converging on the whole interval uniformly with respect to $t \in[0, T]$. If it is known that the sequence $\left\{\phi_{n}\right\}$ converges at least at one point from $[0, T]$, then,

(1) $\left\{\phi_{n}\right\}$ uniformly converges on the whole interval;

(2) $\phi$ is differentiable. Moreover,

$$
\phi^{\prime}(t)=\lim _{n \rightarrow \infty} \phi_{n}^{\prime}(t)
$$

Lemma 2.5. Let $f \in L^{\infty}([0, T] ; E)$. Then the following equality

$$
\left(\frac{d}{d t}\right)\left(\int_{0}^{t}(t-s)^{q-1} E_{q, q}\left(\lambda(t-s)^{q}\right) f(s) d s\right)=\int_{0}^{t}(t-s)^{q-2} E_{q, q-1}\left(\lambda(t-s)^{q}\right) f(s) d s
$$

holds.

Proof. Let $f \in L^{\infty}([0, T] ; E)$. By virtue of Lemmas 2.3 and 2.2, there exists a sequence of functions $\left\{f_{n}\right\} \subset C([0, T] ; E)$ such that $f_{n}(t) \rightarrow f(t)$ for a.e. $t \in[0, T]$. By virtue of Lemma 2.1 for each function $f_{n} \in C([0, T] ; E)$, the following equality holds

$$
\left(\frac{d}{d t}\right)\left(\int_{0}^{t}(t-s)^{q-1} E_{q, q}\left(\lambda(t-s)^{q}\right) f_{n}(s) d s\right)=\int_{0}^{t}(t-s)^{q-2} E_{q, q-1}\left(\lambda(t-s)^{q}\right) f_{n}(s) d s
$$

From Lebesgue's theorem, we have

$$
\lim _{n \rightarrow \infty}\left(\int_{0}^{t}(t-s)^{q-1} E_{q, q}\left(\lambda(t-s)^{q}\right) f_{n}(s) d s\right)=\int_{0}^{t}(t-s)^{q-1} E_{q, q}\left(\lambda(t-s)^{q}\right) f(s) d s
$$

and

$$
\lim _{n \rightarrow \infty}\left(\int_{0}^{t}(t-s)^{q-2} E_{q, q-1}\left(\lambda(t-s)^{q}\right) f_{n}(s) d s\right)=\int_{0}^{t}(t-s)^{q-2} E_{q, q-1}\left(\lambda(t-s)^{q}\right) f(s) d s
$$


uniformly with respect to $t \in[0, T]$. Using Lemma 2.4, we get

$$
\begin{aligned}
& \left(\frac{d}{d t}\right)\left(\int_{0}^{t}(t-s)^{q-1} E_{q, q}\left(\lambda(t-s)^{q}\right) f(s) d s\right) \\
& =\lim _{n \rightarrow \infty}\left(\frac{d}{d t}\right)\left(\int_{0}^{t}(t-s)^{q-1} E_{q, q}\left(\lambda(t-s)^{q}\right) f_{n}(s) d s\right) \\
& =\lim _{n \rightarrow \infty}\left(\int_{0}^{t}(t-s)^{q-2} E_{q, q-1}\left(\lambda(t-s)^{q}\right) f_{n}(s) d s\right) \\
& =\int_{0}^{t}(t-s)^{q-2} E_{q, q-1}\left(\lambda(t-s)^{q}\right) f(s) d s
\end{aligned}
$$

uniformly with respect to $t \in[0, T]$.

2.2. Measures of noncompactness and condensing maps. Let $\mathscr{E}$ be a Banach space. We list the following notations:

- $P(\mathscr{E})=\{A \subseteq \mathscr{E}: A \neq \varnothing\}$;

- $\operatorname{Pb}(\mathscr{E})=\{A \in P(\mathscr{E}): A$ is bounded $\}$;

- $P v(\mathscr{E})=\{A \in P(\mathscr{E}): A$ is convex $\}$

- $K(\mathscr{E})=\{A \in P b(\mathscr{E}): A$ is compact $\}$;

- $K v(\mathscr{E})=P v(\mathscr{E}) \cap K(\mathscr{E})$.

Definition 2.5. $[27,28]$ Let $(\mathscr{A}, \geq)$ be a partially ordered set. A function $\beta: \mathrm{Pb}(\mathscr{E}) \rightarrow \mathscr{A}$ is called a measure of noncompactness (MNC) in $\mathscr{E}$ if, for each $\Omega \in \mathrm{Pb}(\mathscr{E})$, we have

$$
\beta(\overline{\mathrm{co}} \Omega)=\beta(\Omega)
$$

where $\overline{\mathrm{co}} \Omega$ denotes the closure of the convex hull of $\Omega$.

A measure of noncompactness $\beta$ is called:

(1) monotone if, for each $\Omega_{0}, \Omega_{1} \in \operatorname{Pb}(\mathscr{E}), \Omega_{0} \subseteq \Omega_{1}$ implies $\beta\left(\Omega_{0}\right) \leq \beta\left(\Omega_{1}\right)$;

(2) nonsingular if, for each $a \in \mathscr{E}$ and each $\Omega \in \operatorname{Pb}(\mathscr{E}), \beta(\{a\} \cup \Omega)=\beta(\Omega)$.

If $\mathscr{A}$ is a cone in a Banach space, then the MNC $\beta$ is called:

(3) regular if $\beta(\Omega)=0$ is equivalent to the relative compactness of $\Omega \in \mathrm{Pb}(\mathscr{E})$;

(4) real if $\mathscr{A}$ is the set of all real numbers $\mathbb{R}$ with the natural ordering;

(5) algebraically semiadditive if $\beta\left(\Omega_{0}+\Omega_{1}\right) \leq \beta\left(\Omega_{0}\right)+\beta\left(\Omega_{1}\right)$ for every $\Omega_{0}, \Omega_{1} \in \operatorname{Pb}(\mathscr{E})$.

As an example of a real MNC obeying all above properties, we can consider the Hausdorff $\operatorname{MNC} \chi(\Omega)$ :

$$
\chi(\Omega)=\inf \{\varepsilon>0 \text {, for which } \Omega \text { has a finite } \varepsilon \text {-net in } \mathscr{E}\} .
$$

Note that the Hausdorff MNC satisfies the semi-homogeneity property, i.e.,

$$
\chi(\lambda \Omega)=|\lambda| \chi(\Omega),
$$

for every $\lambda \in \mathbb{R}$ and $\Omega \in \operatorname{Pb}(\mathscr{E})$. More generally, if $\mathscr{L}: \mathscr{E} \rightarrow \mathscr{E}$ is a bounded linear operator, then

$$
\chi(\mathscr{L}(\Omega))=\|\mathscr{L}\| \chi(\Omega)
$$

for every $\Omega \in \mathrm{Pb}(\mathscr{E})$.

Recall that the norm of a set $M \in \mathrm{Pb}(\mathscr{E})$ is defined by

$$
\|M\|=\sup _{x \in M}\|x\|_{\mathscr{E}} .
$$


The following definition and statements can be found in monographs [27, 28].

Definition 2.6. Let $X$ be a closed subset of $\mathscr{E}$ and $\beta$ a MNC in $\mathscr{E}$. A map $f: X \rightarrow E$ is said to be condensing w.r.t. $\beta$ (or $\beta$-condensing) if, for every $\Omega \in P b(X)$ which is not relatively compact, $\beta(f(\Omega)) \nsupseteq \beta(\Omega)$.

Theorem 2.1. [27, 28] Let $\mathscr{M}$ be a convex closed bounded subset of $\mathscr{E}$ and let $f: \mathscr{M} \rightarrow \mathscr{M}$ be continuous $\beta$-condensing map, where $\beta$ is nonsingular MNC in $\mathscr{E}$. Then, the fixed point set Fix $f=\{x: x=f(x)\}$ is non-empty.

Lemma 2.6. [27, Theorem 4.2.1] Let $\left\{\xi_{n}\right\} \subset L^{1}([0, T] ; \mathscr{E})$ be a sequence of $L^{1}$-integrably bounded functions. Suppose that

$$
\chi\left(\left\{\xi_{n}(t)\right\}\right) \leq \alpha(t)
$$

for a.e. $t \in[0, T]$, where $\alpha \in L_{+}^{1}([0, T] ; \mathscr{E})$. Then, for each $\delta>0$, there exist a compact set $K_{\delta} \subset \mathscr{E}$, a set $m_{\delta} \subset[0, T]$ with meas $\left(m_{\delta}\right)<\delta$, and a set of functions $G_{\delta} \subset L^{1}([0, T] ; \mathscr{E})$ with values in $K_{\delta}$ such that, for each $n \geq 1$, there exists a function $b_{n} \in G_{\delta}$ for which

$$
\left\|\xi_{n}(t)-b_{n}(t)\right\|_{\mathscr{E}} \leq 2 \alpha(t)+\delta, \quad t \in[0, T] \backslash m_{\delta} .
$$

Moreover, $\left\{b_{n}\right\}$ can be chosen so that $b_{n} \equiv 0$ on $m_{\delta}$ and this sequence is $L^{1}$ - weakly compact.

\section{GREEN'S FUNCTION}

Let us consider a version of a boundary value problem (2.2)-(2.3) in a separable Banach space $E$ :

$$
\begin{gathered}
{ }^{C} D^{q} x(t)=\lambda x(t)+f(t), \quad t \in[0, T], \quad 1<q<2, \\
x(0)=c_{1}, \quad x^{\prime}(0)=c_{2} .
\end{gathered}
$$

Definition 3.1. A solution to boundary value problem (3.1)- (3.2) is a function $x \in C([0, T] ; E)$ satisfying

$$
x(t)=c_{1} E_{q}\left(\lambda t^{q}\right)+c_{2} t E_{q, 2}\left(\lambda t^{q}\right)+\int_{0}^{t}(t-s)^{q-1} E_{q, q}\left(\lambda(t-s)^{q}\right) f(s) d s .
$$

Lemma 3.1. Let $f \in C([0, T] ; E)$ and

$$
\left(1-E_{q}\left(\lambda T^{q}\right)\right)^{2}-E_{q, 0}\left(\lambda T^{q}\right) E_{q, 2}\left(\lambda T^{q}\right) \neq 0 .
$$

Then the following boundary value problem

$$
\begin{gathered}
{ }^{C} D^{q} x(t)=\lambda x(t)+f(t), \quad t \in[0, T], \quad 1<q<2, \\
x(0)=x(T), \quad x^{\prime}(0)=x^{\prime}(T),
\end{gathered}
$$

has the unique solution

$$
x(t)=\int_{0}^{T} G(t, s) f(s) d s,
$$


where Green's function $G(t, s)$ has the following form

$$
G(t, s)=\left\{\begin{array}{l}
\frac{\left(1-E_{q}\left(\lambda T^{q}\right)\right)(T-s)^{q-1} E_{q, q}\left(\lambda(T-s)^{q}\right)+T E_{q, 2}\left(\lambda T^{q}\right)(T-s)^{q-2} E_{q, q-1}\left(\lambda(T-s)^{q}\right)}{\left(1-E_{q}\left(\lambda T^{q}\right)\right)^{2}-E_{q, 0}\left(\lambda T^{q}\right) E_{q, 2}\left(\lambda T^{q}\right)} E_{q}\left(\lambda t^{q}\right) \\
+\frac{\left.\left(1-E_{q}\left(\lambda T^{q}\right)\right)(T-s)^{q-2} E_{q, q-1}\left(\lambda(T-s)^{q}\right)+T^{-1} E_{q, 0}\left(\lambda T^{q}\right)\right)(T-s)^{q-1} E_{q, q}\left(\lambda(T-s)^{q}\right)}{\left(1-E_{q}\left(\lambda T^{q}\right)\right)^{2}-E_{q, 0}\left(\lambda T^{q}\right) E_{q, 2}\left(\lambda T^{q}\right)} t E_{q, 2}\left(\lambda t^{q}\right) \\
+(t-s)^{q-1} E_{q, q}\left(\lambda(t-s)^{q}\right), \\
\frac{\left(1-E_{q}\left(\lambda T^{q}\right)\right)(T-s)^{q-1} E_{q, q}\left(\lambda(T-s)^{q}\right)+T E_{q, 2}\left(\lambda T^{q}\right)(T-s)^{q-2} E_{q, q-1}\left(\lambda(T-s)^{q}\right)}{\left(1-E_{q}\left(\lambda T^{q}\right)\right)^{2}-E_{q, 0}\left(\lambda T^{q}\right) E_{q, 2}\left(\lambda T^{q}\right)} E_{q}\left(\lambda t^{q}\right) \\
+\frac{\left.\left(1-E_{q}\left(\lambda T^{q}\right)\right)(T-s)^{q-2} E_{q, q-1}\left(\lambda(T-s)^{q}\right)+T^{-1} E_{q, 0}\left(\lambda T^{q}\right)\right)(T-s)^{q-1} E_{q, q}\left(\lambda(T-s)^{q}\right)}{\left(1-E_{q}\left(\lambda T^{q}\right)\right)^{2}-E_{q, 0}\left(\lambda T^{q}\right) E_{q, 2}\left(\lambda T^{q}\right)} t E_{q, 2}\left(\lambda t^{q}\right), \\
0 \leq t<s<T .
\end{array}\right.
$$

Proof. The solution of boundary value problem (3.1) - (3.2) in a Banach space $E$ has the form

$$
x(t)=c_{1} E_{q}\left(\lambda t^{q}\right)+c_{2} t E_{q, 2}\left(\lambda t^{q}\right)+\int_{0}^{t}(t-s)^{q-1} E_{q, q}\left(\lambda(t-s)^{q}\right) f(s) d s .
$$

From (2.6) and Lemma 2.1, we find the derivative

$$
x^{\prime}(t)=c_{1} t^{-1} E_{q, 0}\left(\lambda t^{q}\right)+c_{2} E_{q, 1}\left(\lambda t^{q}\right)+\int_{0}^{t}(t-s)^{q-2} E_{q, q-1}\left(\lambda(t-s)^{q}\right) f(s) d s .
$$

From the property $\frac{1}{\Gamma(0)}=0$, we have the representation

$$
E_{q, 0}\left(\lambda t^{q}\right)=\sum_{n=0}^{\infty} \frac{\left(\lambda t^{q}\right)^{n}}{\Gamma(q n)}=\frac{1}{\Gamma(0)}+\sum_{n=1}^{\infty} \frac{\left(\lambda t^{q}\right)^{n}}{\Gamma(q n)}=\sum_{n=1}^{\infty} \frac{\left(\lambda t^{q}\right)^{n}}{\Gamma(q n)}
$$

Therefore,

$$
t^{-1} E_{q, 0}\left(\lambda t^{q}\right)=\sum_{n=1}^{\infty} \frac{\lambda^{n} t^{q n-1}}{\Gamma(q n)}
$$

It follows that

$$
x(0)=c_{1}, \quad x^{\prime}(0)=c_{2} .
$$

By using boundary conditions (3.5), we get

$$
\left\{\begin{array}{l}
c_{1}=c_{1} E_{q}\left(\lambda T^{q}\right)+c_{2} T E_{q, 2}\left(\lambda T^{q}\right)+\int_{0}^{T}(T-s)^{q-1} E_{q, q}\left(\lambda(T-s)^{q}\right) f(s) d s \\
c_{2}=c_{1} T^{-1} E_{q, 0}\left(\lambda T^{q}\right)+c_{2} E_{q, 1}\left(\lambda T^{q}\right)+\int_{0}^{T}(T-s)^{q-2} E_{q, q-1}\left(\lambda(T-s)^{q}\right) f(s) d s .
\end{array}\right.
$$

We can present the corresponding values of the determinants to solve the system by using the Cramer rule

$$
\begin{gathered}
\Delta=\left(1-E_{q}\left(\lambda T^{q}\right)\right)^{2}-E_{q, 0}\left(\lambda T^{q}\right) E_{q, 2}\left(\lambda T^{q}\right) \\
\Delta_{1}=\left(1-E_{q}\left(\lambda T^{q}\right)\right) \int_{0}^{T}(T-s)^{q-1} E_{q, q}\left(\lambda(T-s)^{q}\right) f(s) d s \\
+T E_{q, 2}\left(\lambda T^{q}\right) \int_{0}^{T}(T-s)^{q-2} E_{q, q-1}\left(\lambda(T-s)^{q}\right) f(s) d s
\end{gathered}
$$




$$
\begin{aligned}
\Delta_{2}= & \left(1-E_{q}\left(\lambda T^{q}\right)\right) \int_{0}^{T}(T-s)^{q-2} E_{q, q-1}\left(\lambda(T-s)^{q}\right) f(s) d s \\
& +T^{-1} E_{q, 0}\left(\lambda T^{q}\right) \int_{0}^{T}(T-s)^{q-1} E_{q, q}\left(\lambda(T-s)^{q}\right) f(s) d s .
\end{aligned}
$$

Now, we get the values of the variables:

$$
\begin{aligned}
c_{1}= & \frac{\Delta_{1}}{\Delta} \\
= & \frac{\left(1-E_{q}\left(\lambda T^{q}\right)\right) \int_{0}^{T}(T-s)^{q-1} E_{q, q}\left(\lambda(T-s)^{q}\right) f(s) d s}{\left(1-E_{q}\left(\lambda T^{q}\right)\right)^{2}-E_{q, 0}\left(\lambda T^{q}\right) E_{q, 2}\left(\lambda T^{q}\right)} \\
& +\frac{T E_{q, 2}\left(\lambda T^{q}\right) \int_{0}^{T}(T-s)^{q-2} E_{q, q-1}\left(\lambda(T-s)^{q}\right) f(s) d s}{\left(1-E_{q}\left(\lambda T^{q}\right)\right)^{2}-E_{q, 0}\left(\lambda T^{q}\right) E_{q, 2}\left(\lambda T^{q}\right)}
\end{aligned}
$$

and

$$
\begin{aligned}
c_{2}= & \frac{\Delta_{2}}{\Delta} \\
= & \frac{\left(1-E_{q}\left(\lambda T^{q}\right)\right) \int_{0}^{T}(T-s)^{q-2} E_{q, q-1}\left(\lambda(T-s)^{q}\right) f(s) d s}{\left(1-E_{q}\left(\lambda T^{q}\right)\right)^{2}-E_{q, 0}\left(\lambda T^{q}\right) E_{q, 2}\left(\lambda T^{q}\right)} \\
& +\frac{T^{-1} E_{q, 0}\left(\lambda T^{q}\right) \int_{0}^{T}(T-s)^{q-1} E_{q, q}\left(\lambda(T-s)^{q}\right) f(s) d s}{\left(1-E_{q}\left(\lambda T^{q}\right)\right)^{2}-E_{q, 0}\left(\lambda T^{q}\right) E_{q, 2}\left(\lambda T^{q}\right)} .
\end{aligned}
$$

Substituting the obtained coefficients to the solution, we arrive at

$$
\begin{aligned}
x(t)=\frac{\left(1-E_{q}\left(\lambda T^{q}\right)\right) \int_{0}^{T}(T-s)^{q-1} E_{q, q}\left(\lambda(T-s)^{q}\right) f(s) d s}{\left(1-E_{q}\left(\lambda T^{q}\right)\right)^{2}-E_{q, 0}\left(\lambda T^{q}\right) E_{q, 2}\left(\lambda T^{q}\right)} E_{q}\left(\lambda t^{q}\right) \\
+\frac{T E_{q, 2}\left(\lambda T^{q}\right) \int_{0}^{T}(T-s)^{q-2} E_{q, q-1}\left(\lambda(T-s)^{q}\right) f(s) d s}{\left(1-E_{q}\left(\lambda T^{q}\right)\right)^{2}-E_{q, 0}\left(\lambda T^{q}\right) E_{q, 2}\left(\lambda T^{q}\right)} E_{q}\left(\lambda t^{q}\right) \\
+\frac{\left(1-E_{q}\left(\lambda T^{q}\right)\right) \int_{0}^{T}(T-s)^{q-2} E_{q, q-1}\left(\lambda(T-s)^{q}\right) f(s) d s}{\left(1-E_{q}\left(\lambda T^{q}\right)\right)^{2}-E_{q, 0}\left(\lambda T^{q}\right) E_{q, 2}\left(\lambda T^{q}\right)} t E_{q, 2}\left(\lambda t^{q}\right) \\
+\frac{T^{-1} E_{q, 0}\left(\lambda T^{q}\right) \int_{0}^{T}(T-s)^{q-1} E_{q, q}\left(\lambda(T-s)^{q}\right) f(s) d s}{\left(1-E_{q}\left(\lambda T^{q}\right)\right)^{2}-E_{q, 0}\left(\lambda T^{q}\right) E_{q, 2}\left(\lambda T^{q}\right)} t E_{q, 2}\left(\lambda t^{q}\right) \\
+\int_{0}^{t}(t-s)^{q-1} E_{q, q}\left(\lambda(t-s)^{q}\right) f(s) d s=\int_{0}^{T} G(t, s) f(s) d s .
\end{aligned}
$$

Arguing in the same way as in the proof of Lemma 2.5, we can construct Green's function for boundary value problem (3.4) - (3.5). It has the same form as in the previous lemma, but under the condition that $f \in L^{\infty}([0, T] ; E)$.

\section{EXISTENCE RESUlT}

We will assume that the nonlinearity $f:[0, T] \times E \rightarrow E$ from problem (1.1) - (1.2) obeys the following conditions:

$(f 1)$ for each $x \in E, f(\cdot, x):[0, T] \rightarrow E$ is measurable;

$(f 2)$ for a.e. $t \in[0, T], f(t, \cdot): E \rightarrow E$ is continuous; 
$(f 3)$ for each $r>0$, there exists a function $\omega_{r} \in L_{+}^{\infty}([0, T] ; E)$ such that, for each $x \in E$ with $\|x\| \leq r$

$$
\|f(t, x)\|_{E} \leq \omega_{r}(t) \text {, for a.e. } t \in[0, T]
$$

$(f 4)$ there exists a function $\mu \in L_{+}^{\infty}([0, T])$ such that, for each bounded set $\Omega \subset E$,

$$
\chi(f(t, \Omega)) \leq \mu(t) \chi(\Omega)
$$

for a.e. $t \in[0, T]$, where $\chi$ is the Hausdorff MNC in $E$.

Consider the operator $F$ defined in the following way

$$
\begin{aligned}
F x(t)=\frac{\left(1-E_{q}\left(\lambda T^{q}\right)\right) \int_{0}^{T}(T-s)^{q-1} E_{q, q}\left(\lambda(T-s)^{q}\right) f(s, x(s)) d s}{\left(1-E_{q}\left(\lambda T^{q}\right)\right)^{2}-E_{q, 0}\left(\lambda T^{q}\right) E_{q, 2}\left(\lambda T^{q}\right)} E_{q}\left(\lambda t^{q}\right) \\
\quad+\frac{T E_{q, 2}\left(\lambda T^{q}\right) \int_{0}^{T}(T-s)^{q-2} E_{q, q-1}\left(\lambda(T-s)^{q}\right) f(s, x(s)) d s}{\left(1-E_{q}\left(\lambda T^{q}\right)\right)^{2}-E_{q, 0}\left(\lambda T^{q}\right) E_{q, 2}\left(\lambda T^{q}\right)} E_{q}\left(\lambda t^{q}\right) \\
+\frac{\left(1-E_{q}\left(\lambda T^{q}\right)\right) \int_{0}^{T}(T-s)^{q-2} E_{q, q-1}\left(\lambda(T-s)^{q}\right) f(s, x(s)) d s}{\left(1-E_{q}\left(\lambda T^{q}\right)\right)^{2}-E_{q, 0}\left(\lambda T^{q}\right) E_{q, 2}\left(\lambda T^{q}\right)} t E_{q, 2}\left(\lambda t^{q}\right) \\
+\frac{T^{-1} E_{q, 0}\left(\lambda T^{q}\right) \int_{0}^{T}(T-s)^{q-1} E_{q, q}\left(\lambda(T-s)^{q}\right) f(s, x(s)) d s}{\left(1-E_{q}\left(\lambda T^{q}\right)\right)^{2}-E_{q, 0}\left(\lambda T^{q}\right) E_{q, 2}\left(\lambda T^{q}\right)} t E_{q, 2}\left(\lambda t^{q}\right) \\
\quad+\int_{0}^{t}(t-s)^{q-1} E_{q, q}\left(\lambda(t-s)^{q}\right) f(s, x(s)) d s=\int_{0}^{T} G(t, s) f(s, x(s)) d s .
\end{aligned}
$$

Note that it follows from conditions $(f 1)-(f 4)$ that, for $x \in C([0, T] ; E), f(\cdot, x(\cdot)) \in L^{\infty}([0, T] ; E)$. At the same time, the formula of the Green function implies, for each $t \in[0, T]$, that $G(t, \cdot)$ is not continuous only at $s=T$, and this point is a summable singularly. Therefore, $F: C([0, T] ; E) \rightarrow$ $C([0, T] ; E)$. Obviously, if a function $x \in C([0, T] ; E)$ is a solution of problem (1.1) - (1.2), then it is a fixed point of the operator $F$. Therefore, in the what follows, we will prove the existence of fixed points of operator $F$.

Let us prove if the following condition holds

$(A)$ if Green function $G$ does not change its sign on the interval $[0, T]$;

then $G$ satisfies the equality

$$
\int_{0}^{T}|G(t, s)| d s=\frac{1}{\lambda} .
$$


Indeed,

$$
\begin{aligned}
\int_{0}^{T} G(t, s) d s= & \frac{\left(1-E_{q}\left(\lambda T^{q}\right)\right) \int_{0}^{T}(T-s)^{q-1} E_{q, q}\left(\lambda(T-s)^{q}\right) d s}{\left(1-E_{q}\left(\lambda T^{q}\right)\right)^{2}-E_{q, 0}\left(\lambda T^{q}\right) E_{q, 2}\left(\lambda T^{q}\right)} E_{q}\left(\lambda t^{q}\right) \\
& +\frac{T E_{q, 2}\left(\lambda T^{q}\right) \int_{0}^{T}(T-s)^{q-2} E_{q, q-1}\left(\lambda(T-s)^{q}\right) d s}{\left(1-E_{q}\left(\lambda T^{q}\right)\right)^{2}-E_{q, 0}\left(\lambda T^{q}\right) E_{q, 2}\left(\lambda T^{q}\right)} E_{q}\left(\lambda t^{q}\right) \\
& +\frac{\left(1-E_{q}\left(\lambda T^{q}\right)\right) \int_{0}^{T}(T-s)^{q-2} E_{q, q-1}\left(\lambda(T-s)^{q}\right) d s}{\left(1-E_{q}\left(\lambda T^{q}\right)\right)^{2}-E_{q, 0}\left(\lambda T^{q}\right) E_{q, 2}\left(\lambda T^{q}\right)} t E_{q, 2}\left(\lambda t^{q}\right) \\
& +\frac{T^{-1} E_{q, 0}\left(\lambda T^{q}\right) \int_{0}^{T}(T-s)^{q-1} E_{q, q}\left(\lambda(T-s)^{q}\right) d s}{\left(1-E_{q}\left(\lambda T^{q}\right)\right)^{2}-E_{q, 0}\left(\lambda T^{q}\right) E_{q, 2}\left(\lambda T^{q}\right)} t E_{q, 2}\left(\lambda t^{q}\right) \\
& +\int_{0}^{t}(t-s)^{q-1} E_{q, q}\left(\lambda(t-s)^{q}\right) d s
\end{aligned}
$$

Further, let us calculate the integrals in the last expression by means of (2.7):

$$
\begin{aligned}
\int_{0}^{T}(T-s)^{q-1} E_{q, q}\left(\lambda(T-s)^{q}\right) d s & =-\int_{0}^{T}(T-s)^{q-1} E_{q, q}\left(\lambda(T-s)^{q}\right) d(T-s) \\
& =\int_{0}^{T} y^{q-1} E_{q, q}\left(\lambda y^{q}\right) d y=T^{q} E_{q, q+1}\left(\lambda T^{q}\right) .
\end{aligned}
$$

Similarly, we have

$$
\begin{gathered}
\int_{0}^{T}(T-s)^{q-2} E_{q, q-1}\left(\lambda(T-s)^{q}\right) d s=T^{q-1} E_{q, q}\left(\lambda T^{q}\right), \\
\int_{0}^{t}(t-s)^{q-1} E_{q, q}\left(\lambda(t-s)^{q}\right) d s=t^{q} E_{q, q+1}\left(\lambda t^{q}\right) .
\end{gathered}
$$

Now, notice that, if we will take $\beta=1$ in (2.5), we get

$$
E_{q}\left(\lambda T^{q}\right)=\frac{1}{\Gamma(1)}+\lambda T^{q} E_{q, q+1}\left(\lambda t^{q}\right)=1+\lambda T^{q} E_{q, q+1}\left(\lambda T^{q}\right)
$$

and

$$
E_{q}\left(\lambda t^{q}\right)=\frac{1}{\Gamma(1)}+\lambda t^{q} E_{q, q+1}\left(\lambda t^{q}\right)=1+\lambda t^{q} E_{q, q+1}\left(\lambda t^{q}\right) .
$$

By using property (2.1), if we will take $\beta=0$ in (2.5), then

$$
E_{q, 0}\left(\lambda T^{q}\right)=\frac{1}{\Gamma(0)}+\lambda T^{q} E_{q, q}\left(\lambda T^{q}\right)=\lambda T^{q} E_{q, q}\left(\lambda T^{q}\right) .
$$

Thus, we get the following equalities

$$
\begin{gathered}
\int_{0}^{T}(T-s)^{q-1} E_{q, q}\left(\lambda(T-s)^{q}\right) d s=T^{q} \frac{1}{\lambda T^{q}}\left(E_{q}\left(\lambda T^{q}\right)-1\right)=\frac{1}{\lambda}\left(E_{q}\left(\lambda T^{q}\right)-1\right), \\
\int_{0}^{T}(T-s)^{q-2} E_{q, q-1}\left(\lambda(T-s)^{q}\right) d s=\frac{1}{\lambda T} E_{q, 0}\left(\lambda T^{q}\right)
\end{gathered}
$$

and

$$
\int_{0}^{t}(t-s)^{q-1} E_{q, q}\left(\lambda(t-s)^{q}\right) d s=\frac{1}{\lambda}\left(E_{q}\left(\lambda t^{q}\right)-1\right) .
$$


It follows that

$$
\begin{aligned}
& \int_{0}^{T} G(t, s) d s \\
& =\frac{\left(1-E_{q}\left(\lambda T^{q}\right)\right) \frac{1}{\lambda}\left(E_{q}\left(\lambda T^{q}\right)-1\right)+T E_{q, 2}\left(\lambda T^{q}\right) \frac{1}{\lambda T} E_{q, 0}\left(\lambda T^{q}\right)}{\left(1-E_{q}\left(\lambda T^{q}\right)\right)^{2}-E_{q, 0}\left(\lambda T^{q}\right) E_{q, 2}\left(\lambda T^{q}\right)} E_{q}\left(\lambda t^{q}\right) \\
& \quad+\frac{\left(1-E_{q}\left(\lambda T^{q}\right)\right) \frac{1}{\lambda T} E_{q, 0}\left(\lambda T^{q}\right)+T^{-1} E_{q, 0}\left(\lambda T^{q}\right) \frac{1}{\lambda}\left(E_{q}\left(\lambda T^{q}\right)-1\right)}{\left(1-E_{q}\left(\lambda T^{q}\right)\right)^{2}-E_{q, 0}\left(\lambda T^{q}\right) E_{q, 2}\left(\lambda T^{q}\right)} t E_{q, 2}\left(\lambda t^{q}\right) \\
& \quad+\frac{1}{\lambda}\left(E_{q}\left(\lambda t^{q}\right)-1\right) \\
& =-\frac{1}{\lambda} E_{q}\left(\lambda t^{q}\right) \frac{\left(1-E_{q}\left(\lambda T^{q}\right)\right)^{2}-E_{q, 0}\left(\lambda T^{q}\right) E_{q, 2}\left(\lambda T^{q}\right)}{\left(1-E_{q}\left(\lambda T^{q}\right)\right)^{2}-E_{q, 0}\left(\lambda T^{q}\right) E_{q, 2}\left(\lambda T^{q}\right)} \\
& \quad+t E_{q, 2}\left(\lambda t^{q}\right) \frac{\left(1-E_{q}\left(\lambda T^{q}\right)\right)(\lambda T)^{-1} E_{q, 0}\left(\lambda T^{q}\right)-\left(1-E_{q}\left(\lambda T^{q}\right)\right)(\lambda T)^{-1} E_{q, 0}\left(\lambda T^{q}\right)}{\left(1-E_{q}\left(\lambda T^{q}\right)\right)^{2}-E_{q, 0}\left(\lambda T^{q}\right) E_{q, 2}\left(\lambda T T^{q}\right)} \\
& \quad+\frac{1}{\lambda}\left(E_{q}\left(\lambda t^{q}\right)-1\right)=-\frac{1}{\lambda} E_{q}\left(\lambda t^{q}\right)+\frac{1}{\lambda}\left(E_{q}\left(\lambda t^{q}\right)-1\right)=-\frac{1}{\lambda} .
\end{aligned}
$$

Then, (4.1) holds obviously. To prove the existence of a fixed point of the operator $F$, we introduce the operator $S: L^{\infty}([0, T] ; E) \rightarrow C([0, T] ; E)$ of the form

$$
S(f)(t)=\int_{0}^{t}(t-s)^{q-1} E_{q, q}\left(\lambda(t-s)^{q}\right) f(s) d s .
$$

Lemma 4.1. Let a sequence $\left\{\eta_{n}\right\} \subset L^{\infty}([0, T] ; E)$ be bounded and $\eta_{n} \rightarrow \eta_{0}$ in $L^{1}([0, T] ; E)$. Then $S\left(\eta_{n}\right) \rightarrow S\left(\eta_{0}\right)$ in $C([0, T] ; E)$.

Proof. For $d>0$, consider the operator $S_{d}: L^{1}([0, T] ; E) \rightarrow C([0, T] ; E)$ defined by

$$
S_{d}\left(\eta_{n}\right)= \begin{cases}0, & t \leq d \\ \int_{0}^{t-d}(t-s)^{q-1} E_{q, q}\left(\lambda(t-s)^{q}\right) \eta_{n}(s) d s, & t>d\end{cases}
$$

Since the integrand in the last expression is the function continuous on $[0, t-d]$, we have

$$
S_{d}\left(\eta_{n}\right) \rightarrow S_{d}\left(\eta_{0}\right)
$$

in the space $C([0, T] ; E)$. Let $\psi$ be a continuous linear functional on $C([0, T] ; E)$, i.e., $\psi \in$ $C^{*}([0, T] ; E)$. Then, we have

$$
\left(\psi, S\left(\eta_{n}\right)\right)=\left(\psi, S_{d}\left(\eta_{n}\right)\right)+\left(\psi, S\left(\eta_{n}\right)-S_{d}\left(\eta_{n}\right)\right), n=0,1,2, \ldots
$$

From the definition of the operator $S_{d}$, we conclude

$$
\left(S\left(\eta_{n}\right)-S_{d}\left(\eta_{n}\right)\right)(t)= \begin{cases}\int_{0}^{t}(t-s)^{q-1} E_{q, q}\left(\lambda(t-s)^{q}\right) \eta_{n}(s) d s, & t \leq d \\ \int_{t-d}^{t}(t-s)^{q-1} E_{q, q}\left(\lambda(t-s)^{q}\right) \eta_{n}(s) d s, & t>d .\end{cases}
$$

Then, we obtain the following estimates

$$
\begin{aligned}
\left\|S\left(\eta_{n}\right)-S_{d}\left(\eta_{n}\right)\right\|_{C([0, T] ; E)} & \leq\left\{\begin{array}{l}
\int_{0}^{t}(t-s)^{q-1} E_{q, q}\left(\lambda(t-s)^{q}\right)\left\|\eta_{n}(s)\right\|_{E} d s, t \leq d, \\
\int_{t-d}^{t}(t-s)^{q-1} E_{q, q}\left(\lambda(t-s)^{q}\right)\left\|\eta_{n}(s)\right\|_{E} d s, t>d,
\end{array}\right. \\
& \leq d^{q} E_{q, q}\left(\lambda T^{q}\right)\left\|\eta_{n}\right\|_{L^{\infty}([0, T] ; E)} .
\end{aligned}
$$


Therefore, for an arbitrary $\varepsilon>0$, we may choose such $d>0$ that the following estimate holds true:

$$
\left\|S\left(\eta_{n}\right)-S_{d}\left(\eta_{n}\right)\right\|_{C([0, T] ; E)} \leq \frac{\varepsilon}{4\|\psi\|_{C^{*}([0, T] ; E)}} .
$$

By virtue of (4.3), we have $\left(\psi, S_{d}\left(\eta_{n}\right)\right) \rightarrow\left(\psi, S_{d}\left(\eta_{0}\right)\right)$. For a given $\varepsilon$, we may choose number $n_{0}$ such that

$$
\left(\psi, S_{d}\left(\eta_{n_{0}}\right)-S_{d}\left(\eta_{0}\right)\right)<\varepsilon / 2
$$

By using (4.4), (4.5) and (4.6), we obtain

$$
\begin{aligned}
\left(\psi, S\left(\eta_{n}\right)-S\left(\eta_{0}\right)\right) & =\left(\psi, S_{d}\left(\eta_{n}\right)-S_{d}\left(\eta_{0}\right)\right)+\left(\psi, S\left(\eta_{n}\right)-S_{d}\left(\eta_{n}\right)\right)+\left(\psi, S_{d}\left(\eta_{0}\right)-S\left(\eta_{0}\right)\right) \\
& <\frac{\varepsilon}{2}+2\|\psi\|_{C^{*}([0, T] ; E)} \frac{\varepsilon}{4\|\psi\|_{C^{*}([0, T] ; E)}} \\
& =\varepsilon
\end{aligned}
$$

which concludes the proof.

Lemma 4.2. For each compact set $K \subset E$ and bounded sequence $\left\{\eta_{n}\right\} \subset L^{\infty}([0, T] ; E)$ such that $\left\{\eta_{n}(t)\right\} \subset K$ for a.e. $t \in[0, T]$, the weak convergence $\eta_{n} \rightarrow \eta_{0}$ in $L^{1}([0, T] ; E)$ implies the convergence $S\left(\eta_{n}\right) \rightarrow S\left(\eta_{0}\right)$ in $C([0, T] ; E)$.

Proof. From the definition of the Mittag-Leffler function, we obtain

$$
\chi\left(\left\{S\left(\eta_{n}\right)(t)\right\}\right) \leq \int_{0}^{t}(t-s)^{q-1} \chi\left(\left\{E_{q, q}\left(\lambda(t-s)^{q}\right) \eta_{n}(s)\right\}\right) d s=0
$$

This means that the sequence $\left\{S\left(\eta_{n}\right)(t)\right\}_{n=1}^{\infty} \subset E$ is relatively compact for each $t \in[0, T]$. From the other side, if we take $t_{1}, t_{2} \in[0, T]$ such that $0<t_{1}<t_{2} \leq T$, then

$$
\begin{aligned}
\| S & \left.\eta_{n}\right)\left(t_{2}\right)-S\left(\eta_{n}\right)\left(t_{1}\right) \|_{E} \\
= & \left\|\int_{0}^{t_{2}}\left(t_{2}-s\right)^{q-1} E_{q, q}\left(\lambda\left(t_{2}-s\right)^{q}\right) \eta_{n}(s) d s-\int_{0}^{t_{1}}\left(t_{1}-s\right)^{q-1} E_{q, q}\left(\lambda\left(t_{1}-s\right)^{q}\right) \eta_{n}(s) d s\right\|_{E} \\
= & \left\|\int_{t_{1}}^{t_{2}}\left(t_{2}-s\right)^{q-1} E_{q, q}\left(\lambda\left(t_{2}-s\right)^{q}\right) \eta_{n}(s) d s\right\|_{E} \\
& +\left\|\int_{0}^{t_{1}}\left(\left(t_{2}-s\right)^{q-1} E_{q, q}\left(\lambda\left(t_{2}-s\right)^{q}\right)-\left(t_{1}-s\right)^{q-1} E_{q, q}\left(\lambda\left(t_{1}-s\right)^{q}\right)\right) \eta_{n}(s) d s\right\|_{E} \\
\leq & \left\|\int_{t_{1}}^{t_{2}}\left(t_{2}-s\right)^{q-1} E_{q, q}\left(\lambda\left(t_{2}-s\right)^{q}\right) \eta_{n}(s) d s\right\|_{E} \\
& +\left\|\int_{0}^{t_{1}}\left(\left(t_{2}-s\right)^{q-1}-\left(t_{1}-s\right)^{q-1}\right) E_{q, q}\left(\lambda\left(t_{1}-s\right)^{q}\right) \eta_{n}(s) d s\right\|_{E} \\
& +\left\|\int_{0}^{t_{1}}\left(t_{2}-s\right)^{q-1}\left(E_{q, q}\left(\lambda\left(t_{2}-s\right)^{q}\right)-E_{q, q}\left(\lambda\left(t_{1}-s\right)^{q}\right)\right) \eta_{n}(s) d s\right\|_{E} \\
= & Z_{1}+Z_{2}+Z_{3},
\end{aligned}
$$


where

and

$$
\begin{gathered}
Z_{1}=\left\|\int_{t_{1}}^{t_{2}}\left(t_{2}-s\right)^{q-1} E_{q, q}\left(\lambda\left(t_{2}-s\right)^{q}\right) \eta_{n}(s) d s\right\|_{E}, \\
Z_{2}=\left\|\int_{0}^{t_{1}}\left(\left(t_{2}-s\right)^{q-1}-\left(t_{1}-s\right)^{q-1}\right) E_{q, q}\left(\lambda\left(t_{1}-s\right)^{q}\right) \eta_{n}(s) d s\right\|_{E},
\end{gathered}
$$

$$
Z_{3}=\left\|\int_{0}^{t_{1}}\left(t_{2}-s\right)^{q-1}\left(E_{q, q}\left(\lambda\left(t_{2}-s\right)^{q}\right)-E_{q, q}\left(\lambda\left(t_{1}-s\right)^{q}\right)\right) \eta_{n}(s) d s\right\|_{E} .
$$

By using condition $(f 3)$, we can choose for a given $\varepsilon_{1}>0$ a number $\delta_{1}>0$ such that $\left|t_{2}-t_{1}\right|<$ $\delta_{1}$ implies the following estimate

$$
Z_{1} \leq\left\|\omega_{K}\right\|_{\infty} E_{q, q}\left(\lambda T^{q}\right) \frac{\left(t_{2}-t_{1}\right)^{q}}{q}<\varepsilon_{1}
$$

To estimate $Z_{2}$, we take constant $d>0$

$$
\begin{aligned}
Z_{2} \leq & \left\|\int_{0}^{t_{1}-d}\left(\left(t_{2}-s\right)^{q-1}-\left(t_{1}-s\right)^{q-1}\right) E_{q, q}\left(\lambda\left(t_{1}-s\right)^{q}\right) \eta_{n}(s) d s\right\|_{E} \\
& +\left\|\int_{t_{1}-d}^{t_{1}}\left(\left(t_{2}-s\right)^{q-1}-\left(t_{1}-s\right)^{q-1}\right) E_{q, q}\left(\lambda\left(t_{1}-s\right)^{q}\right) \eta_{n}(s) d s\right\|_{E} \\
= & I_{1}+I_{2},
\end{aligned}
$$

where

$$
I_{1}=\left\|\int_{0}^{t_{1}-d}\left(\left(t_{2}-s\right)^{q-1}-\left(t_{1}-s\right)^{q-1}\right) E_{q, q}\left(\lambda\left(t_{1}-s\right)^{q}\right) \eta_{n}(s) d s\right\|_{E}
$$

and

$$
I_{2}=\left\|\int_{t_{1}-d}^{t_{1}}\left(\left(t_{2}-s\right)^{q-1}-\left(t_{1}-s\right)^{q-1}\right) E_{q, q}\left(\lambda\left(t_{1}-s\right)^{q}\right) \eta_{n}(s) d s\right\|_{E} .
$$

Consider the function $v:[d, T] \rightarrow E, v(\tau)=\tau^{q-1}$. This function is continuous on the interval $[d, T]$. Hence, by the Cantor theorem, it is uniformly continuous on this interval, i.e., for each $\gamma>0$, there exists $\delta_{2}>0$ such that $\left|\tau_{2}-\tau_{1}\right|<\delta_{2}<d, \tau_{1}, \tau_{2} \in[d, T]$ implies

$$
\left|\tau_{2}^{q-1}-\tau_{1}^{q-1}\right|<\gamma
$$

Now, taking $\tau=t-s$, we get

$$
I_{1} \leq\left\|\omega_{K}\right\|_{\infty} \gamma\left(t_{1}-d\right) E_{q, q}\left(\lambda T^{q}\right)<\varepsilon_{2} .
$$

By the direct integration, for $I_{2}$, we obtain

$$
I_{2} \leq \frac{\left\|\omega_{K}\right\|_{\infty} E_{q, q}\left(\lambda T^{q}\right) d^{q}\left(2+2^{q}\right)}{q}<\varepsilon_{3} .
$$

Taking into account the definition of the Mittag-Leffler function, we conclude that, for each $x \in K$ and $\gamma_{1}>0$, there exists $\delta_{3}>0$ such that $\left|t_{2}-t_{1}\right|<\delta_{3}$ implies

$$
\left\|E_{q, q}\left(\lambda\left(t_{2}-s\right)^{q}\right) x-E_{q, q}\left(\lambda\left(t_{1}-s\right)^{q}\right) x\right\|<\gamma_{1}, x \in K .
$$


So, we get

$$
Z_{3} \leq \gamma_{1} T^{q}<\varepsilon_{4}
$$

Therefore, for each $\varepsilon>0$, we may choose $\delta=\min \left\{\delta_{1}, \delta_{2}, \delta_{3}\right\}$ such that

$$
\begin{aligned}
\left\|S\left(\eta_{n}\right)\left(t_{2}\right)-S\left(\eta_{n}\right)\left(t_{1}\right)\right\|_{E} & \leq Z_{1}+Z_{2}+Z_{3} \\
& <\varepsilon_{1}+\varepsilon_{2}+\varepsilon_{3}+\varepsilon_{4} \\
& <\varepsilon .
\end{aligned}
$$

So, $\left\{S\left(\eta_{n}\right)\right\}$ is equicontinuous. From the Arzela-Ascoli theorem, we conclude that the sequence $\left\{S\left(\eta_{n}\right)\right\} \subset C([0, T] ; E)$ is relatively compact. From Lemma 4.1, we know that the weak convergence $\eta_{n} \rightarrow \eta_{0}$ implies $S\left(\eta_{n}\right) \rightarrow S\left(\eta_{0}\right)$. Since $\left\{S\left(\eta_{n}\right)\right\}$ is relatively compact, we conclude that $S\left(\eta_{n}\right) \rightarrow S\left(\eta_{0}\right)$ in $C([0, T] ; E)$.

To prove that the operator $F$ is condensing, we consider the cone

$$
\mathbb{R}_{+}^{2}=\left\{\zeta=\left(\zeta_{1}, \zeta_{2}\right): \zeta_{1} \geq 0, \zeta_{2} \geq 0\right\}
$$

endowed with the natural ordering and introduce in the space $C([0, T] ; E)$, the vector measure of noncompactness

$$
v: P(C([0, T] ; E)) \rightarrow \mathbb{R}_{+}^{2}
$$

defined as

$$
v(\Omega)=\left(\varphi(\Omega), \bmod _{C}(\Omega)\right),
$$

where $\varphi(\Omega)$ is the module of fiber noncompactness

$$
\varphi(\Omega)=\sup _{t \in[0, T]} \chi(\{y(t): y \in \Omega\})
$$

and the second component is the module of equicontinuity

$$
\bmod _{C}(\Omega)=\lim _{\delta \rightarrow 0} \sup _{y \in \Omega} \max _{\left|t_{1}-t_{2}\right| \leq \delta}\left\|y\left(t_{1}\right)-y\left(t_{2}\right)\right\| .
$$

Theorem 4.1. Under assumptions $(f 1)-(f 4),(3.3)$, and $(A)$, suppose, in addition, that the following condition

$$
\frac{\|\mu\|_{\infty}}{\lambda}<1
$$

holds true, where $\mu(\cdot)$ is the function from condition $(f 4)$. Then, the operator $F$ is $v$-condensing.

Proof. Let $\Omega \subset C([0, T] ; E)$ be a nonempty bounded set such that

$$
v(F(\Omega)) \geq v(\Omega) .
$$

Let us show that $\Omega$ is relatively compact. From (4.9), it follows that

$$
\varphi(F(\Omega)) \geq \varphi(\Omega)
$$

By using properties $(f 4)$ and (4.1), we get

$$
\begin{aligned}
\chi(F(\Omega)(t)) & \leq \chi\left(\int_{0}^{T} G(t, s) f(s, \Omega(s)) d s\right) \leq\|\mu\|_{\infty} \int_{0}^{T}|G(t, s)| \chi(\Omega(s)) d s \\
& \leq\|\mu\|_{\infty} \varphi(\Omega) \int_{0}^{T}|G(t, s)| d s=\frac{\|\mu\|_{\infty}}{\lambda} \varphi(\Omega) .
\end{aligned}
$$


From the last estimate, we obtain

$$
\sup _{t \in[0, T]} \chi(F(\Omega)(t)) \leq \frac{\|\mu\|_{\infty}}{\lambda} \varphi(\Omega)
$$

or

$$
\varphi(F(\Omega)) \leq \frac{\|\mu\|_{\infty}}{\lambda} \varphi(\Omega) .
$$

Conditions (4.8) and (4.10) obviously imply

$$
\varphi(\Omega)=0 .
$$

Now, from (4.9), we have

$$
\bmod _{C}(F(\Omega)) \geq \bmod _{C}(\Omega)
$$

We next show that

$$
\bmod _{C}(F(\Omega))=0 .
$$

This means that we must demonstrate that the set of functions

$$
M=\left\{S(f)(t)=\int_{0}^{t}(t-s)^{q-1} E_{q, q}\left(\lambda(t-s)^{q}\right) f(s, x(s)) d s: x \in \Omega\right\}
$$

is equicontinuous. Let us fix $\varepsilon>0$. If we take $t_{1}, t_{2} \in[0, T]$ such that $0<t_{1}<t_{2} \leq T$, then, for arbitrary $x \in \Omega$,

$$
\begin{aligned}
& \left\|S(f)\left(t_{2}\right)-S(f)\left(t_{1}\right)\right\|_{E} \\
& \leq\left\|\int_{0}^{t_{2}}\left(t_{2}-s\right)^{q-1} E_{q, q}\left(\lambda\left(t_{2}-s\right)^{q}\right) f(s, x(s)) d s-\int_{0}^{t_{1}}\left(t_{1}-s\right)^{q-1} E_{q, q}\left(\lambda\left(t_{1}-s\right)^{q}\right) f(s, x(s)) d s\right\|_{E} \\
& \leq\left\|\int_{t_{1}}^{t_{2}}\left(t_{2}-s\right)^{q-1} E_{q, q}\left(\lambda\left(t_{2}-s\right)^{q}\right) f(s, x(s)) d s\right\|_{E} \\
& \quad+\left\|\int_{0}^{t_{1}}\left(\left(t_{2}-s\right)^{q-1} E_{q, q}\left(\lambda\left(t_{2}-s\right)^{q}\right)-\left(t_{1}-s\right)^{q-1} E_{q, q}\left(\lambda\left(t_{1}-s\right)^{q}\right)\right) f(s, x(s)) d s\right\|_{E} \\
& =Z_{1}+Z_{2},
\end{aligned}
$$

where

$$
Z_{1}=\left\|\int_{t_{1}}^{t_{2}}\left(t_{2}-s\right)^{q-1} E_{q, q}\left(\lambda\left(t_{2}-s\right)^{q}\right) f(s, x(s)) d s\right\|_{E}
$$

and

$$
Z_{2}=\left\|\int_{0}^{t_{1}}\left(\left(t_{2}-s\right)^{q-1} E_{q, q}\left(\lambda\left(t_{2}-s\right)^{q}\right)-\left(t_{1}-s\right)^{q-1} E_{q, q}\left(\lambda\left(t_{1}-s\right)^{q}\right)\right) f(s, x(s)) d s\right\|_{E} .
$$

By using condition $(f 3)$, we can take $\delta_{1}>0$ such that the condition $\left|t_{2}-t_{1}\right|<\delta_{1}$ implies the following estimate

$$
Z_{1} \leq\left\|\omega_{r_{\Omega}}\right\|_{\infty} E_{q, q}\left(\lambda T^{q}\right) \frac{\left(t_{2}-t_{1}\right)^{q}}{q}<\frac{\varepsilon}{6}
$$


To estimate $Z_{2}$, we choose

$$
d<\delta_{2}:=\left[\frac{\frac{\varepsilon}{6} q}{\left\|\omega_{r_{\Omega}}\right\|_{\infty} E_{q, q}\left(\lambda T^{q}\right)\left(2^{q}+1\right)}\right]^{\frac{1}{q}} .
$$

Then, for $t_{1}<d$ and $t_{2}-t_{1}<d$,

$$
\begin{aligned}
Z_{2} \leq & \int_{0}^{t_{1}}\left(t_{2}-s\right)^{q-1}\left\|E_{q, q}\left(\lambda\left(t_{2}-s\right)^{q}\right)\right\| \cdot\|f(s, x(s))\|_{E} d s \\
& +\int_{0}^{t_{1}}\left(t_{1}-s\right)^{q-1}\left\|E_{q, q}\left(\lambda\left(t_{1}-s\right)^{q}\right)\right\| \cdot\|f(s, x(s))\|_{E} d s \\
\leq & \int_{0}^{t_{2}}\left(t_{2}-s\right)^{q-1}\left\|E_{q, q}\left(\lambda\left(t_{2}-s\right)^{q}\right)\right\| \cdot\|f(s, x(s))\|_{E} d s \\
& +\int_{0}^{t_{1}}\left(t_{1}-s\right)^{q-1}\left\|E_{q, q}\left(\lambda\left(t_{1}-s\right)^{q}\right)\right\| \cdot\|f(s, x(s))\|_{E} d s \\
\leq & \left\|\omega_{r_{\Omega}}\right\|_{\infty} E_{q, q}\left(\lambda T^{q}\right)\left(2^{q}+1\right) \frac{d^{q}}{q} \\
< & \frac{\varepsilon}{6} .
\end{aligned}
$$

For $t_{1}>d$, we get

$$
\begin{aligned}
Z_{2} \leq & \left\|\int_{0}^{t_{1}-d}\left(\left(t_{2}-s\right)^{q-1} E_{q, q}\left(\lambda\left(t_{2}-s\right)^{q}\right)-\left(t_{1}-s\right)^{q-1} E_{q, q}\left(\lambda\left(t_{1}-s\right)^{q}\right)\right) f(s, x(s)) d s\right\|_{E} \\
& +\left\|\int_{t_{1}-d}^{t_{1}}\left(\left(t_{2}-s\right)^{q-1} E_{q, q}\left(\lambda\left(t_{2}-s\right)^{q}\right)-\left(t_{1}-s\right)^{q-1} E_{q, q}\left(\lambda\left(t_{1}-s\right)^{q}\right)\right) f(s, x(s)) d s\right\|_{E} \\
= & I_{1}+I_{2},
\end{aligned}
$$

where

$$
I_{1}=\left\|\int_{0}^{t_{1}-d}\left(\left(t_{2}-s\right)^{q-1} E_{q, q}\left(\lambda\left(t_{2}-s\right)^{q}\right)-\left(t_{1}-s\right)^{q-1} E_{q, q}\left(\lambda\left(t_{1}-s\right)^{q}\right)\right) f(s, x(s)) d s\right\|_{E}
$$

and

$$
I_{2}=\left\|\int_{t_{1}-d}^{t_{1}}\left(\left(t_{2}-s\right)^{q-1} E_{q, q}\left(\lambda\left(t_{2}-s\right)^{q}\right)-\left(t_{1}-s\right)^{q-1} E_{q, q}\left(\lambda\left(t_{1}-s\right)^{q}\right)\right) f(s, x(s)) d s\right\|_{E} .
$$

Take $d$ small enough such that

$$
I_{2} \leq \frac{\left\|\omega_{r_{\Omega}}\right\|_{\infty} E_{q, q}\left(\lambda T^{q}\right) d^{q}\left(2+2^{q}\right)}{q}<\frac{\varepsilon}{6} .
$$

Since $\chi(\Omega(t)) \equiv 0$, we conclude from Lemma 2.6 that, for every $\delta_{3}>0$, there exist a compact set $K_{\delta_{3}} \subset E$, a set $m_{\delta_{3}} \subseteq[0, T]$ of Lebesgue's measure mes $\left(m_{\delta_{3}}\right)<\delta_{3}$, and a set of functions $\Delta \subset L^{1}([0, T] ; E)$ with values in $K_{\delta_{3}}$ such that there exists a function $b \in \Delta$ for which

$$
\|f(t, x(t))-b(t)\|_{E} \leq \delta_{3}, \quad t \in[0, T] \backslash m_{\delta_{3}} .
$$

Moreover, the function $b \in \Delta$ could be chosen so that $b(t) \equiv 0$ on $m_{\delta_{3}}$ and the set $\Delta$ is weakly compact in $L^{1}([0, T] ; E)$. Then, for $I_{1}$, the following estimate holds 


$$
\begin{aligned}
& I_{1} \leq\left\|\int_{0}^{t_{1}-d}\left(\left(t_{2}-s\right)^{q-1} E_{q, q}\left(\lambda\left(t_{2}-s\right)^{q}\right)-\left(t_{1}-s\right)^{q-1} E_{q, q}\left(\lambda\left(t_{1}-s\right)^{q}\right)\right)(f(s, x(s))-b(s)) d s\right\|_{E} \\
& +\left\|\int_{0}^{t_{1}-d}\left(\left(t_{2}-s\right)^{q-1} E_{q, q}\left(\lambda\left(t_{2}-s\right)^{q}\right)-\left(t_{1}-s\right)^{q-1} E_{q, q}\left(\lambda\left(t_{1}-s\right)^{q}\right)\right) b(s) d s\right\|_{E} \\
& \leq \| \int_{\left[0, t_{1}-d\right] \backslash m_{\delta_{3}}}\left(\left(t_{2}-s\right)^{q-1} E_{q, q}\left(\lambda\left(t_{2}-s\right)^{q}\right)\right. \\
& \left.-\left(t_{1}-s\right)^{q-1} E_{q, q}\left(\lambda\left(t_{1}-s\right)^{q}\right)\right)(f(s, x(s))-b(s)) d s \|_{E} \\
& +\| \int_{\left[0, t_{1}-d\right] \cap m_{\delta_{3}}}\left(\left(t_{2}-s\right)^{q-1} E_{q, q}\left(\lambda\left(t_{2}-s\right)^{q}\right)\right. \\
& \left.-\left(t_{1}-s\right)^{q-1} E_{q, q}\left(\lambda\left(t_{1}-s\right)^{q}\right)\right)(f(s, x(s))-b(s)) d s \|_{E} \\
& +\left\|\int_{\left[0, t_{1}-d\right] \backslash m_{\delta_{3}}}\left(\left(t_{2}-s\right)^{q-1} E_{q, q}\left(\lambda\left(t_{2}-s\right)^{q}\right)-\left(t_{1}-s\right)^{q-1} E_{q, q}\left(\lambda\left(t_{1}-s\right)^{q}\right)\right) b(s) d s\right\|_{E} \\
& +\left\|\int_{\left[0, t_{1}-d\right] \cap m_{\delta_{3}}}\left(\left(t_{2}-s\right)^{q-1} E_{q, q}\left(\lambda\left(t_{2}-s\right)^{q}\right)-\left(t_{1}-s\right)^{q-1} E_{q, q}\left(\lambda\left(t_{1}-s\right)^{q}\right)\right) b(s) d s\right\|_{E} \\
& =\| \int_{\left[0, t_{1}-d\right] \backslash m_{\delta_{3}}}\left(\left(t_{2}-s\right)^{q-1} E_{q, q}\left(\lambda\left(t_{2}-s\right)^{q}\right)\right. \\
& \left.-\left(t_{1}-s\right)^{q-1} E_{q, q}\left(\lambda\left(t_{1}-s\right)^{q}\right)\right)(f(s, x(s))-b(s)) d s \|_{E} \\
& +\| \int_{\left[0, t_{1}-d\right] \cap m_{\delta_{3}}}\left(\left(t_{2}-s\right)^{q-1} E_{q, q}\left(\lambda\left(t_{2}-s\right)^{q}\right)\right. \\
& \left.-\left(t_{1}-s\right)^{q-1} E_{q, q}\left(\lambda\left(t_{1}-s\right)^{q}\right)\right)(f(s, x(s))-b(s)) d s \|_{E} \\
& +\left\|\int_{\left[0, t_{1}-d\right] \backslash m_{\delta_{3}}}\left(\left(t_{2}-s\right)^{q-1} E_{q, q}\left(\lambda\left(t_{2}-s\right)^{q}\right)-\left(t_{1}-s\right)^{q-1} E_{q, q}\left(\lambda\left(t_{1}-s\right)^{q}\right)\right) b(s) d s\right\|_{E} \\
& =N_{1}+N_{2}+N_{3} \text {, }
\end{aligned}
$$

where

$$
\begin{aligned}
N_{1}= & \| \int_{\left[0, t_{1}-d\right] \backslash m_{\delta_{3}}}\left(\left(t_{2}-s\right)^{q-1} E_{q, q}\left(\lambda\left(t_{2}-s\right)^{q}\right)\right. \\
& \left.-\left(t_{1}-s\right)^{q-1} E_{q, q}\left(\lambda\left(t_{1}-s\right)^{q}\right)\right)(f(s, x(s))-b(s)) d s \|_{E}
\end{aligned}
$$




$$
\begin{aligned}
N_{2}= & \| \int_{\left[0, t_{1}-d\right] \cap m_{\delta_{3}}}\left(\left(t_{2}-s\right)^{q-1} E_{q, q}\left(\lambda\left(t_{2}-s\right)^{q}\right)\right. \\
& \left.-\left(t_{1}-s\right)^{q-1} E_{q, q}\left(\lambda\left(t_{1}-s\right)^{q}\right)\right)(f(s, x(s))-b(s)) d s \|_{E}
\end{aligned}
$$

and

$$
N_{3}=\left\|\int_{\left[0, t_{1}-d\right] \backslash m_{\delta_{3}}}\left(\left(t_{2}-s\right)^{q-1} E_{q, q}\left(\lambda\left(t_{2}-s\right)^{q}\right)-\left(t_{1}-s\right)^{q-1} E_{q, q}\left(\lambda\left(t_{1}-s\right)^{q}\right)\right) b(s) d s\right\|_{E} .
$$

By using (4.13), we find small $\delta_{3}>0$ so that mes $\left(m_{\delta_{3}}\right)<2 \frac{\varepsilon}{6} d^{1-q}$ yields $N_{1}<\frac{\varepsilon}{6}$, and $N_{2}<\frac{\varepsilon}{6}$. Recall that the functions from $\Delta$ take their values in $K_{\delta_{3}}$ that implies $\Delta \subset L^{\infty}([0, T] ; E)$. Then by using Lemma 4.2, we can choose $\delta_{4}>0$ such that $\left|t_{2}-t_{1}\right|<\delta_{4}$ implies $N_{3}<\frac{\varepsilon}{6}$. So, for each $\varepsilon>0$, we may choose $\delta=\min \left\{\delta_{1}, \delta_{2}, \delta_{3}, \delta_{4}\right\}$ such that

$$
\begin{aligned}
\left\|S(f)\left(t_{2}\right)-S(f)\left(t_{1}\right)\right\|_{E} & \leq Z_{1}+Z_{2} \\
& \leq Z_{1}+I_{1}+I_{2} \\
& \leq Z_{1}+I_{2}+N_{1}+N_{2}+N_{3} \\
& <\frac{\varepsilon}{6}+\frac{\varepsilon}{6}+\frac{\varepsilon}{6}+\frac{\varepsilon}{6}+\frac{\varepsilon}{6}+\frac{\varepsilon}{6} \\
& =\varepsilon
\end{aligned}
$$

for each $x \in \Omega$ and $\left|t_{2}-t_{1}\right|<\delta$, i.e., the set $M$ is equicontinuous. From inequality (4.12), it follows that $\bmod _{C}(\Omega)=0$, which further yields $v(\Omega)=(0,0)$. The assertion is proved.

Hence, we have the following result.

Theorem 4.2. Under conditions $(f 1),(f 2), f(4),(3.3)$, and $(A)$, suppose that condition $(f 3)$ has the following form:

$\left(f 3^{\prime}\right)$ there exists a function $\alpha \in L_{+}^{\infty}([0, T])$ such that

$$
\|f(t, x(t))\|_{E} \leq \alpha(t)\left(1+\|x(t)\|_{E}\right)
$$

If $\frac{k}{\lambda}<1$, where $k=\max \left\{\|\alpha\|_{\infty},\|\mu\|_{\infty}\right\}$, functions $\alpha$ and $\mu$ are from conditions $\left(f 3^{\prime}\right)$ and $(f 4)$ respectively, then problem (1.1)-(1.2) has a solution. 
Proof. Taking an arbitrary $x \in C([0, T] ; E)$, we have for $t \in[0, T]$ the following estimate

$$
\begin{aligned}
\|F x(t)\|_{E} & \leq\left\|\int_{0}^{T} G(t, s) f(s, x(s)) d s\right\|_{E} \\
& \leq \int_{0}^{T}|G(t, s)|\|f(s, x(s))\|_{E} d s \\
& \leq \int_{0}^{T}|G(t, s)|\|\alpha\|_{\infty}\left(1+\|x\|_{C([0, T] ; E)}\right) d s \\
& =\|\alpha\|_{\infty}\left(1+\|x\|_{C([0, T] ; E)}\right) \int_{0}^{T}|G(t, s)| d s \\
& =\frac{\|\alpha\|_{\infty}\left(1+\|x\|_{C([0, T] ; E)}\right)}{\lambda} \\
& \leq \frac{k\left(1+\|x\|_{C([0, T] ; E)}\right)}{\lambda} .
\end{aligned}
$$

So, if we will take $R \geq \frac{k \lambda^{-1}}{1-k \lambda^{-1}}$, then $\|x\|_{C([0, T] ; E)} \leq R$ implies $\|F x\|_{C([0, T] ; E)} \leq R$. Therefore, $F$ transforms the closed ball $B_{R}(0) \subset C([0, T] ; E)$ into itself. Now, since $\mathrm{r} F$ is condensing, we conclude from Theorem 2.1 that it has a fixed point, which is a solution of problem (1.1)(1.2).

\section{Acknowledgments}

This work was supported by the State contract of the Russian Ministry of Science and Hight Education as part of the state task (contract FZGF-2020-0009).

\section{REFERENCES}

[1] R. Gorenflo, A.A. Kilbas, F. Mainardi, S.V. Rogosin, Mittag-Leffler Functions, Related Topics and Applications, Springer-Verlag, Berlin Heidelberg, 2014.

[2] R. Hilfer, Applications of Fractional Calculus in Physics, World Scientific, Singapore, 2000.

[3] A.A. Kilbas, H.M. Srivastava, J.J. Trujillo, Theory and Applications of Fractional Differential Equations, Elsevier Science B.V., North-Holland Mathematics Studies, Amsterdam, 2006.

[4] I. Podlubny, Fractional Differential Equations, Academic Press, San Diego, 1999.

[5] V.E. Tarasov, Fractional Dynamics. Applications of Fractional Calculus to Dynamics of Particles, Fields and Media, Springer, London, New York, 2010.

[6] Y. Zhou, Fractional Evolution Equations and Inclusions: Analysis and Control, Elsevier Academic Press, London, 2016.

[7] M. Afanasova, Y.C. Liou, V. Obukhoskii, G. Petrosyan, On controllability for a system governed by a fractional-order semilinear functional differential inclusion in a Banach space, J. Nonlinear Convex Anal. 20 (2019), 1919-1935.

[8] M. Afanasova, G. Petrosyan, On the boundary value problem for functional differential inclusion of fractional order with general initial condition in a Banach space, Russian Math. 63 (2019), 1-12.

[9] J. Appell, B. Lopez, K. Sadarangani, Existence and uniqueness of solutions for a nonlinear fractional initial value problem involving Caputo derivatives, J. Nonlinear Var. Anal. 2 (2018), 25-33.

[10] I. Benedetti, V. Obukhovskii, V. Taddei, On generalized boundary value problems for a class of fractional differential inclusions, Fract. Calc. Appl. Anal. 20 (2017), 1424-1446.

[11] F. Mainardi, On the initial value problem for the fractional diffusion-wave equation. In: Rionero S, Ruggeeri T (ed) Waves and Stability in Continuous Media, pp. 246-251, World Scientific, Singapore, 1994. 
[12] M. Kamenskii, V. Obukhovskii, G. Petrosyan, J.C. Yao, On semilinear fractional order differential inclusions in Banach spaces, Fixed Point Theory 18 (2017), 269-291.

[13] M. Kamenskii, V. Obukhovskii, G. Petrosyan, J.C. Yao, Boundary value problems for semilinear differential inclusions of fractional order in a Banach space, Applicable Anal. 97 (2018), 571-591.

[14] M. Kamenskii, V. Obukhovskii, G. Petrosyan, J.C. Yao, On approximate solutions for a class of semilinear fractional-order differential equations in Banach spaces, Fixed Point Theory Appl. 2017 (2017), 28.

[15] M. Kamenskii, V. Obukhovskii, G. Petrosyan, J.C. Yao, Existence and approximation of solutions to nonlocal boundary value problems for fractional differential inclusions, Fixed Point Theory Appl. 2019 (2019), 2.

[16] Z. Hong, L. Jiao, D.S. Kim, On a class of nonsmooth fractional robust multi-objective optimization problems. Part I: Optimality conditions, Appl. Set-Valued Anal. Optim. 2 (2020), 109-121.

[17] T.D. Ke, N.V. Loi, V. Obukhovskii, Decay solutions for a class of fractional differential variational inequalities, Fract. Calc. Appl. Anal. 18 (2015), 531-553.

[18] T.D. Ke, V. Obukhovskii, N.C. Wong, J.C. Yao, On a class of fractional order differential inclusions with infinite delays, Applicable Anal. 92 (2013), 115-137.

[19] G.G. Petrosyan, M.S. Afanasova, On the Cauchy problem for differential inclusion of fractional order with a nonlinear boundary condition, Bull. Voronezh State Univ. Series Physics. Math. 1 (2017), 135-151. (In Russian)

[20] Z. Zhang, B. Liu, Existence of mild solutions for fractional evolution equations, Fixed Point Theory 15 (2014), 325-334.

[21] M.I. Abbas, Existence results and the Ulam stability for fractional differential equations with hybrid proportional-Caputo derivatives, J. Nonlinear Funct. Anal. 2020 (2020), Article ID 48.

[22] M. Belmekki, J.J. Nieto, R. Rodriguez-Lopez, Existence of periodic solution for a nonlinear fractional differential equation, Boundary Value Problems. 2009 (2009), 324561.

[23] M. Belmekki,J.J. Nieto, R. Rodiguez-Lopez, Existence of solution to a periodic boundary value problem for a nonlinear impulsive fractional differential equation, Electron. J. Qual. Theory Differ. Equ. 16 (2014), 1-27.

[24] Z. Bai, H. Lu, Positive solutions for boundary-value problem of nonlinear fractional differential equation, J. Math. Anal. Appl. 311 (2005), 495-505.

[25] V. M. Bogdan, Generalized vectorial Lebesgue and Bochner integration theory, arXiv:1006.3881v1 [math.FA]. 2010.

[26] G.M. Fichtenholz, Course in Differential and Integral Calculus, Vol. 1, Fizmatlit, Moscow, 2006.

[27] M. Kamenskii, V. Obukhovskii, P. Zecca, Condensing Multivalued Maps and Semilinear Differential Inclusions in Banach Spaces, Walter de Gruyter, Berlin and New York, 2001.

[28] V. Obukhovskii, B. Gelman, Multivalued Maps and Differential Inclusions, Elements of Theory and Applications, World Scientific, Singapore, 2020. 